\title{
Leprosy and disability control in the Guéra Prefecture of Chad, Africa: do women have access to leprosy control services?
}

\author{
JOHANNES SCHÄFER \\ Mission Evangélique Contre la Lèpre/The Leprosy Mission Projet de \\ Lutte contre la Lèpre, Préfecture du Guéra, Mongo, Chad
}

\author{
Accepted for publication 17 July 1998
}

\begin{abstract}
Summary In a retrospective study, data from the Guéra Leprosy and Disability Control Project in Chad, covering the years from 1992 to 1996, were analysed in order to determine whether there was any indication that the quality of care provided to female leprosy sufferers is inferior to the care provided for male patients. Data from a total of 741 patient registered for MDT, of whom 351 were newly diagnosed cases, are presented and discussed. The data indicate that women have access to diagnosis and treatment and health education. They do not present for treatment later than men, disability rates are lower and they have slightly higher treatment completion rates. Both women and men benefit from footwear and loan programs. More women than men are involved in patient self-help groups. The study shows that in this part of central Chad, there is no evidence of disadvantage for women with leprosy in either diagnosis, treatment or follow-up, but more qualitative data is needed to confirm these findings.
\end{abstract}

\section{Introduction}

Systematic discrimination against women has been recognized in many cultures world-wide. While some aspects of discrimination are quite obvious even to the casual observer, more subtle and complex mechanisms exist that are much more difficult to identify. There is an increasing awareness that such discrimination may affect activities that are primarily considered to be gender neutral. Attention has been drawn to the relationship of gender and health and the significant disparities that exist between women and men, ${ }^{1}$ and recent research on gender and tropical disease has highlighted some of the particular disadvantages that women face with respect to risk factors of infection, the social costs of disease and access to care. $^{2-4}$

Within the framework of leprosy control activities, two distinct phases can be identified during which discrimination against women could occur. The first phase of case detection and diagnosis covers the time between the onset of the disease and ends when the diagnosis of leprosy is established and the patient is registered for treatment. The key question during this phase is whether facilities for diagnosis and treatment for leprosy are readily accessible to members of both sexes, or whether there are factors that prevent women from presenting for 
diagnosis and treatment. It has been pointed out that in India, because of fear of social ostracism, women are more likely to hide their disease than men $^{5}$ and that significantly fewer females were detected through voluntary reporting compared to active case detection in the community. ${ }^{6}$ Awofeso notes that in northern Nigeria, female and male patients differ in significant respects in their perception of socio-cultural beliefs about leprosy and discusses the possible implications for health education programmes. ${ }^{7}$ Many of the factors that affect case detection are beyond the direct influence of the leprosy control service, but their recognition and analysis are key elements to eventual improvement.

The second phase is that of treatment and follow-up. The key question here concerns the quality of treatment and care: is it provided regardless of the sex of the patient once the diagnosis has been established, or does overt or hidden discrimination take place, resulting in an inferior quality of care for female leprosy sufferers? A wide variety of mechanisms through which discrimination can occur are conceivable, particularly in a male dominated health care system. As much of this discrimination originates within the service itself, it can be addressed and corrective action can be taken.

In a recent policy statement on gender, The Leprosy Mission International (TLMI) affirms its commitment to 'maximize women's access to leprosy diagnosis, health education, health care and rehabilitation'. ${ }^{8}$ The implementation of such a policy presents a particular challenge to projects working in cultural environments where male dominance in all aspects of public life is an established and unquestionable fact.

This is the case for the Guéra Leprosy and Disability Control Programme, a TLMI project situated in the Guéra Prefecture in central Chad and started in 1992. It has taken an active role in implementing multi-drug therapy (MDT) within the framework of the National Leprosy Control Programme of Chad (NLCP).

There is an extremely high illiteracy rate of $94.8 \%$ among women, compared to $77 \%$ among men and the low school attendance rate for girls. In rural areas, only $15 \%$ of the girls attend primary school, while the rate for boys is $27 \% .^{9}$ Only a small minority of the health care staff are women. Apart from two expatriate workers in our project (POD officer and leprosy supervisor), all NLCP staff at national and provincial level are men.

In the following, I will review some of the activities undertaken by the Guéra Leprosy and Disability Control Project from 1992 to 1996 in order to determine whether the available data provide any indication that quality of care provided to female leprosy sufferers is inferior to the care provided for male patients.

\section{Materials and methods}

\section{BACKGROUND INFORMATION ON THE GUÉRA PREFECTURE}

The Guéra Prefecture, located in central Chad, has a population of 335,000 scattered over an area of $60,000 \mathrm{~km}^{2}$. Women outnumber men by a ratio of $1 \cdot 17: 1$; this is higher than the national female/male ratio, which lies at 1·06:1. ${ }^{10}$ Approximately two-thirds of the population belong to the so called 'Hadjerai' (people of the rock). While this is not a homogeneous group, but is composed of a number of small ethnic groups that speak distinct languages, these groups share many cultural traits. They live as sedentary subsistence farmers, whose main crops are millet, ground nuts and sesame. About $15 \%$ of the population are nomads of predominantly Semitic origin, who raise cattle, goats and camels. The predominant religion is Islam: $90 \%$ of the population are Muslims, 5\% are animists and 
Christians make up 3\%. At least 15 different languages are spoken, chadian Arabic is used as the trade language. There are no surfaced roads and the road network is very poor. Access to many areas is difficult during the dry season and impossible during the rainy season.

At the peripheral level, health care is provided by health centres that serve a defined health zone. However, only 12 out of 32 designated health zones actually have a health centre. The health zones are grouped into three districts, which are theoretically served by a district hospital. However, only one hospital exists for the entire prefecture, and district medical of ficers were only posted in 1996. Even where health facilities exist, quality of health care is often poor due to the lack of qualified staff and material resources.

Leprosy treatment is provided free of charge as one of the services provided by the health centres.

Data provided by the NLCP for all of Chad shows that in December 1995 the prevalence of leprosy was estimated at 4.91 cases per 10,000, with 3238 leprosy patients on register; of these 3104 (96\%) were on MDT. The case detection rate for 1995 was $15 \cdot 4$ per 10,000, with 1015 new cases detected in the course of the year. ${ }^{11}$

GUÉRA LEPROSY AND DISABILITY CONTROL PROJECT

Multi-drug therapy was introduced in the Guéra in 1992 after leprosy work had been disrupted for more than 10 years as a result of the long civil war. A phased approach was adopted for MDT implementation.

In a first phase of MDT implementation, a review of all known cases was undertaken and no particular case finding efforts were made. A cycle of supervision was established, health centre staff was trained and a technical manual ${ }^{12}$ was written that was later adopted by the national leprosy control programme. By June 1994, MDT had been introduced in all health centres.

The second phase was characterized by the transfer of responsibility for treatment to health centre staff and an intensification of case finding through health education of the general public, and continued regular monthly visits by the leprosy supervisor. The third phase of extension of MDT into areas not covered by health services began after MDT and was well established in all health centres. The approach used and the results obtained has been described elsewhere. ${ }^{13}$ By the end of 1996, patients had been put on MDT in all but three of the 32 designated health zones.

\section{DIAGNOSIS, CLASSIFICATION AND TREATMENT}

Responsibility for diagnosis, classification and treatment lay with the leprosy supervisor. The leprosy supervisor in turn is supervised by the medical officer. As a rule, all patients were seen at least once by the medical officer.

Diagnosis, classification and treatment followed the procedures outlined in the Technical Manual. Briefly, diagnosis was based on the presence of at least one of three cardinal signs (anaesthetic lesion, nerve enlargement or the presence of acid fast bacilli in slit skin smears). From mid-1995 onward, all patients with more than five skin lesions were classified as multibacillary (MB), regardless of their bacillary index (BI). Only cases that had no history of previous treatment with anti-leprosy drugs were considered to be new cases. All other cases were regarded as 'old cases', regardless of the duration of previous treatment. Patients were treated using standard WHO-MDT blister packs. Treatment was discontinued after 6 months 
for paucibacillary (PB) cases and after 24 months for MB cases. PB patients who were absent for 3 consecutive months or who could not complete 6 monthly doses in 9 months were considered 'lost to follow-up' (LF). MB patients who could not receive 24 monthly doses within 36 months or who were absent for 6 consecutive months were also considered LF. LF cases were removed from the treatment register and readmitted for another full course of treatment under category 'Readmitted' if they presented at a later stage with signs of active disease.

The clinical examination at the time of diagnosis included recordings of all visible deformity and a nerve function assessment with voluntary muscle testing and sensory testing using graded nylon filaments for all patients. Deformities of eyes, feet and hands were recorded for all patients using the WHO 2 point disability grade, ${ }^{14}$ and the highest of these was also recorded as the overall disability grade of the patient.

PREVENTION OF DISABILITY

From the outset, special attention was given to prevention of disability (POD) activities as an integral part of MDT implementation. This included regular testing for changes in muscle strength of eyelids, hands and feet by a standard set of voluntary muscle tests (VMT) and changes in the sensitivity of palms and soles by sensory testing (ST) with graded nylon filaments for all patients on MDT, health education for patients with existing neurological deficits, a protocol for field treatment of neuritis, provision of locally produced protective footwear for patients with plantar sensory loss and ulcer care.

Two main problems were identified:

The patients were scattered over a vast area and therefore only seen once a month by the leprosy supervisor. Given the high workload, POD activities were often unsystematic and follow-up was poor. Second, patient education required extra time and special skills that the understaffed health centres could not provide. In order to deal with these problems, four health educators were recruited and trained as POD assistants and assigned to certain geographical areas. All four originated from their respective work zones. In training, special emphasis was placed on communication skills.

A task oriented POD Manual ${ }^{15}$ was written, describing in detail all activities and procedures that were considered necessary and practicable, and evaluation parameters were defined. This included a protocol for standardized health education for all patients registered for MDT. At the time of diagnosis, patients received a short education session with four simple messages, and the fact that education had been given was recorded on the patient record. On a subsequent visit to the clinic, comprehension of the health education previously received was evaluated by a set of standardized questions. If any of the responses was incorrect, the health education message was repeated.

\section{METHODS AND STATISTICAL ANALYSIS}

All patient records were specifically designed to facilitate data collection. A computerized relational database containing individual patient data was set up in 1993 using EPI-Info 5. Individual patient data were collected as part of routine activities by the leprosy supervisor when the patient registered for treatment and entered into the database on a quarterly basis. Printouts of data were produced in quarterly intervals and verified during supervisory visits by the medical of ficer. The data collected included general data such as age, sex, distance 
from treatment centre, lifestyle (sedentary or nomadic), and leprosy-related data such as date of diagnosis and start of treatment, time elapsed between first symptoms and diagnosis, history of previous treatment, Bacterial Index, WHO classification, and disability grades for hands, feet and eyes.

With the start of the POD programme in 1994, additional information on health education, supply of footwear and appliances was routinely collected by the POD officer and entered into the database.

Data were compiled from the existing database. Statistical analysis was carried out by the $\chi^{2}$ test using the Epi Info Version 6 package. ${ }^{16}$ The level of significance was set at $95 \%$ $(p<0 \cdot 05)$.

\section{Results}

PATIENTS REGISTERED FOR MDT (FIGURE 1)

Of 351 patients put on MDT from 1992-1996, 206 (59\%) were women or girls with variations in the yearly rate ranging from $48 \%$ (1994) to 64\% (1996). The variation over the years was not statistically significant.

Of the same 351 patients 29 were younger than 15 years at the time of diagnosis, 17 (58\%) of them were girls.

Of 390 readmitted patients put on MDT from 1992 to 1996, 229 (59\%) were women, with the variation ranging from 57 to $61 \%$ (data not shown).

MB/PB RATIOS AMONG NEW CASES (FIGURE 2)

Among the new patients, 108 (31\%) were classified as having multi-bacillary (MB) leprosy. There was a statistically significant difference between men and women, with an MB rate of $26 \%$ among female patients compared to $38 \%$ among male patients.

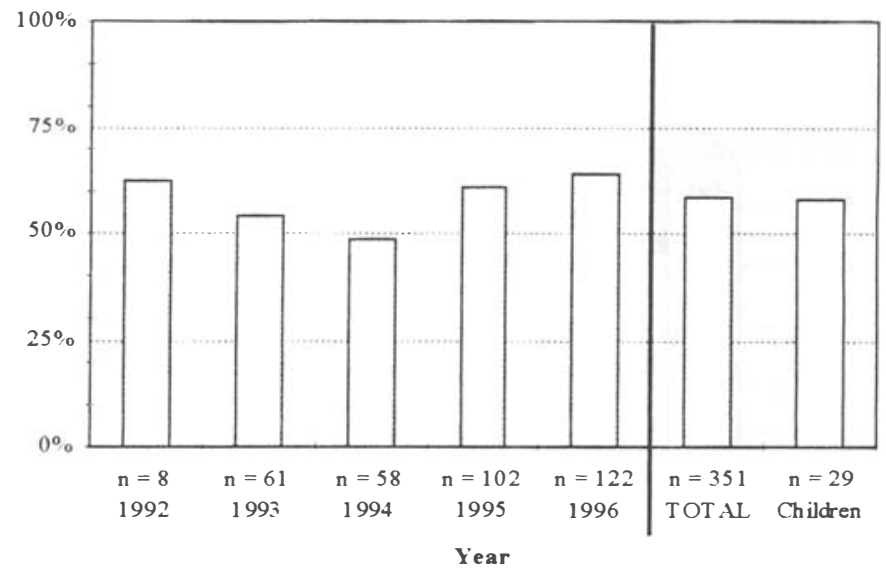

Figure 1. Percentage of women among newly diagnosed leprosy patients, 1992-1996. 


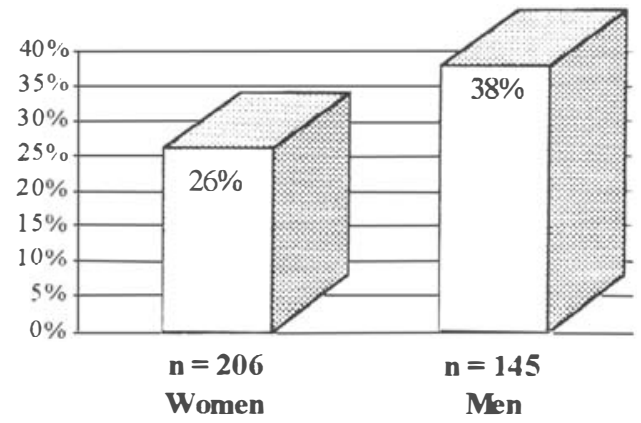

Figure 2. Multibacillary rate among newly diagnosed cases, by gender, 1992-1996.

\section{DISABILITY GRADE AT TIME OF DIAGNOSIS (FIGURE 3)}

A statistically significant lower rate of disability was found among newly diagnosed female patients. Among women, $58 \%$ had no disability or deformity at time of diagnosis (WHO disability grade 0 ), compared to $43 \%$ among new male patients. This difference was more marked among PB cases, where $65 \%$ of women and only $47 \%$ of men had no disability or deformity. Among MB cases, the difference in disability rates were statistically not significant, only $40 \%$ of women and $36 \%$ of men had a disability grade of 0 at the time of diagnosis.

\section{TIME ELAPSED BETWEEN FIRST SYMPTOMS AND DIAGNOSIS (FIGURE 4)}

At the time of diagnosis, all patients were asked how long ago they had noticed the first signs of the disease. Only $13 \%$ of women and $11 \%$ of men had noticed the first signs less than a year ago, while $44 \%$ of women and $43 \%$ of men said that they had been ill for more than 5 years already.

Of the new patients only $12 \%$ had noticed the first signs less than a year ago, while $43 \%$ had been ill for more than 5 years. The small difference observed between female and male patients was not significant.

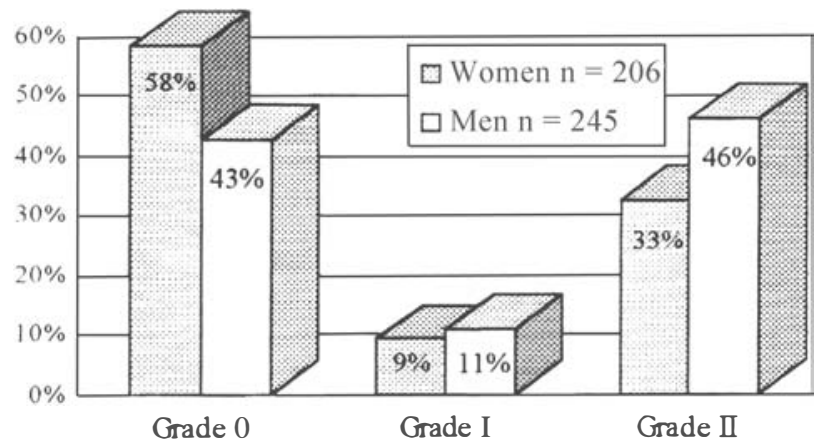

Figure 3. WHO Disability Grade I in newly diagnosed cases, 1992-1996. 


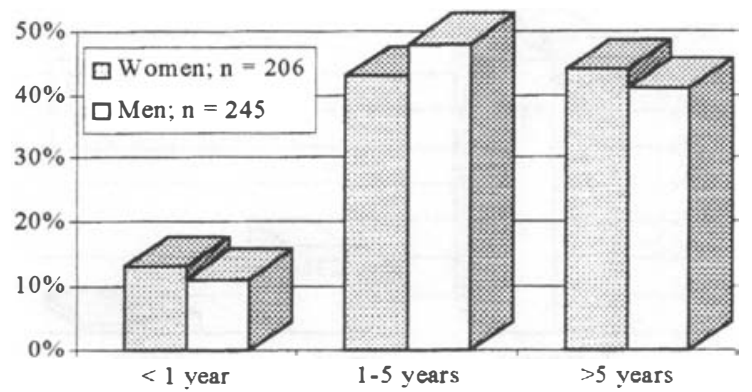

Figure 4. Duration of disease before diagnosis in newly diagnosed leprosy patients, 1992-1996.

TREATMENT COMPLETION RATES, MB CASES (FIGURE 5) AND PB CASES (FIGURE 6)

Treatment compliance can only be studied for those patients that have had the chance to complete their treatment within the defined treatment period, i.e. 36 months for MB cases and 9 months for MB cases. Thus only MB cases that started treatment before 1995 and PB cases that started before 1996 are considered. Of 202 MB cases put on treatment between 19921994, 144 (71\%) received 24 monthly doses of MDT within 36 months. Thirty-eight patients (17\%) were lost to follow-up, either because of more than 6 consecutive months of absence or for more than 12 months cumulated absence from treatment. There were no differences in treatment completion rates and the defaulter rates between men and women. Among the 335 PB cases put on treatment between 1992-1995, treatment completion rates for women were significantly better than treatment completion rates for men (79 versus $74 \%$ ), with higher defaulter rates among male patients.

\section{HEALTH EDUCATION UPON DIAGNOSIS (FIGURE 7)}

Health education using a standardized format was started in 1994. Out of the 260 patients for whom data are available, $90 \%$ of women and $96 \%$ of men registered for MDT received health education at the time of diagnosis; the difference between the sexes was not significant. Only $21 \%$ of women and $23 \%$ of men were able to answer all questions correctly on the subsequent visit.

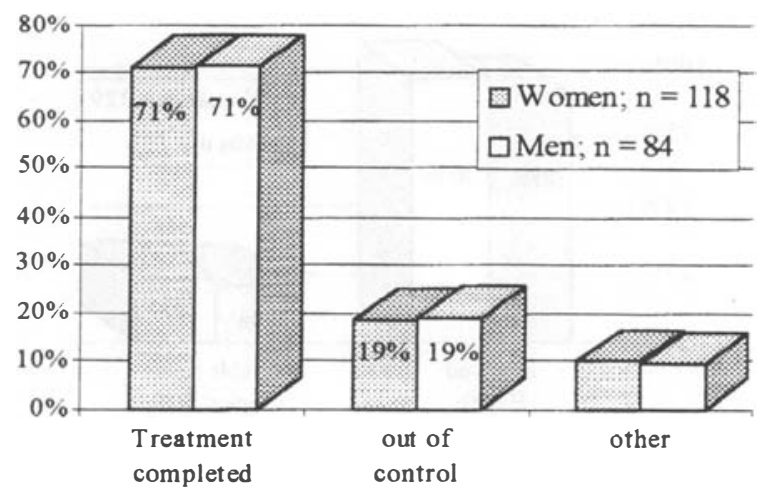

Figure 5. Treatment outcome in multibacillary cases, by gender, 1992-1996. 


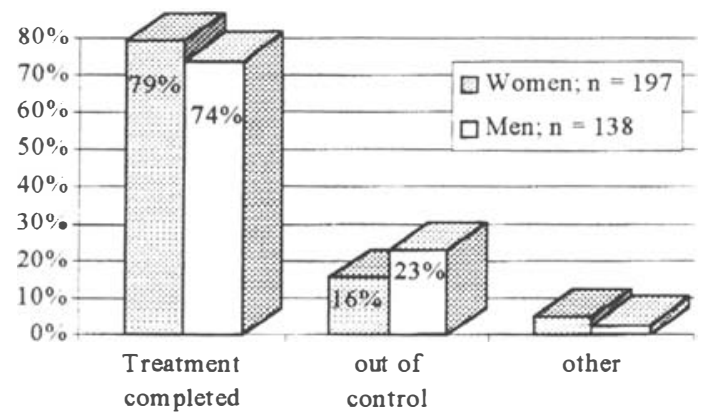

Figure 6. Treatment outcome in paucibacillary cases, by gender, 1992-1996.

PROVISION OF FOOTWEAR TO PATIENTS WITH INSENSITIVE FEET (FIGURE 8)

Locally produced protective footwear was offered to all patients with plantar sensory loss at a nominal price. Out of 370 patients with plantar sensory loss, $167(45 \%)$ have received at least one pair of MCR sandals. The difference observed between women and men ( 44 compared to $47 \%$ ) was not significant.

\section{Discussion}

The overall epidemiological situation regarding sex distribution in leprosy is far from clear. Although leprosy affects both sexes, in most parts of the world, males are affected more frequently than females, often in the ratio of $2: 1$, with the difference being more marked among adults; however, male preponderance is not universal, particularly in Africa. ${ }^{17}$

In Ethiopia, among 286 new cases registered for MDT within the AMFES project from 1988 to 1992 , only $37 \%$ of the patients were women (47\% of the PB cases and $28 \%$ of the MB cases) ${ }^{18}$ and of 5131 patients registered for MDT in the Shoa Administrative Region between $1984-1988,35 \cdot 1 \%$ of the patients were female. ${ }^{19}$ In a limited study conducted in the Sudan in a rural setting that resembles the situation encountered in Chad, $44 \%$ of the 43 cases detected were women. ${ }^{20}$ At the Leprology Unit of the Institut Marchoux in Bamako, which serves as a

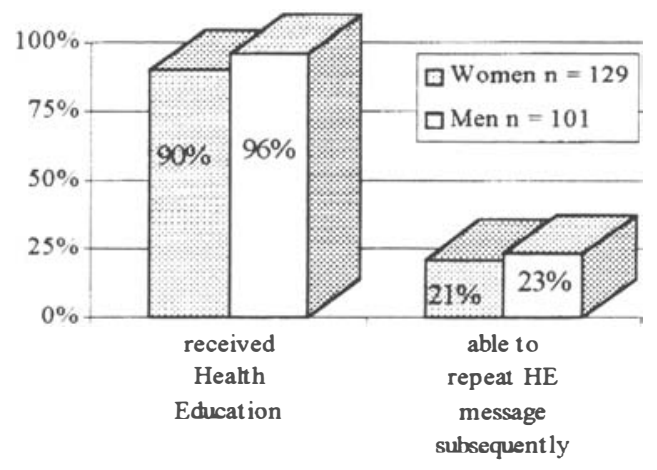

Figure 7. Initial health education. 


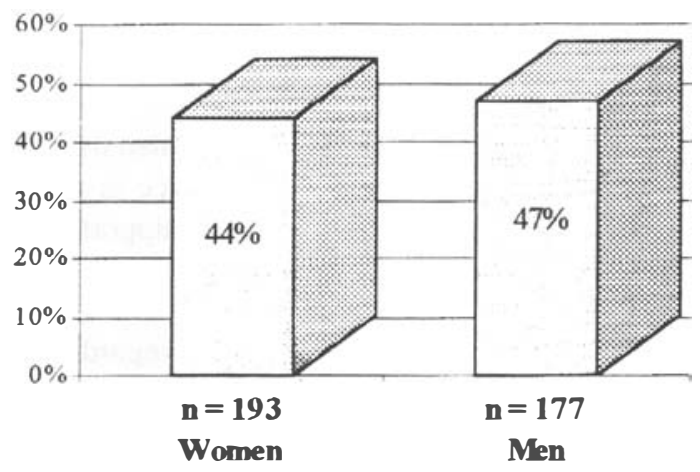

Figure 8. Percentage of patients with insensitive feet who received protective footwear, by gender, 1992-1996.

reference centre for Mali, out of 187 new cases detected between February 1992 and June 1994 , only 56 (30\%) were women. ${ }^{21}$ The authors note that the sample is not representative of leprosy patients diagnosed in the field, but no further details are given. By contrast, data from Karonga district in Malawi, based on total population surveys, show an overall higher incidence of leprosy among women than men, $61 \%$ of all the 489 cases registered were women. However, among the small group of $29 \mathrm{MB}$ cases in this study, only $45 \%$ were women. $^{22}$

Our own data show a clear preponderance of women among the new cases detected, not only young adults but also among children. This has been a consistent finding over the years, and applies not only to new cases but also to patients previously registered for monotherapy.

In comparing the data, it must be borne in mind that case detection rates depend on a number of factors, specifically the way case finding is organized and conducted and the fact that these rates reflect incidence and prevalence only indirectly. However, it is most probably safe to say that if ascertainment bias occurs, it would lead to under-detection of leprosy among females because women generally have less access to health care facilities and because one would expect examination of women to be less complete and less satisfactory in some cultural contexts.

The fact that in our programme more women than men are registered for MDT can be interpreted in a number of different ways. It is possible that these figures reflect an epidemiological situation similar to that encountered in Malawi, where there was higher incidence among women than among men.

It is also possible that the difference is not due to higher incidence but rather to other factors. In conjunction with the significantly lower disability rates observed in women with PB leprosy, it could indicate that women seek treatment earlier than men. However, lower disability rates among female patients have been observed in a variety of different settings such as India, ${ }^{23,24}$ China, $^{25}$ Malawi $^{26}$ and Burkina Faso. ${ }^{27}$ One explanation given for this finding is that women's chances of developing deformities are reduced due to less frequent involvement of nerve trunks. ${ }^{1}$ When questioned about the duration of disease before diagnosis, no difference between the sexes could be elicited. By contrast, a study from Kuwait showed that women clearly had a longer time lag between onset of symptoms and presentation to the physician. ${ }^{28}$ It is possible that the time scale used is too crude to detect subtle differences. 
Factors leading to a lower prevalence among men, such as higher mortality rates among men or a higher rate of migration among men, could also account for higher case detection rates among females.

However, the fact that we observed higher MB rates in men than in women, a finding that is in keeping with the observation that male preponderance is much more pronounced in lepromatous leprosy than in tuberculoid leprosy, does not support this hypothesis, as there is no apparent reason why higher mortality or the migration of men should only affect PB cases.

As our data are based on passive case detection and no data from population surveys are available, it is not possible to make a conclusive statement regarding sex specific prevalence rates, although our findings suggest that more women than men are affected in our area. Whatever the case may be, the fact that we have consistently registered more female than male leprosy cases seems to be an indication that the leprosy control services are readily accessible to women.

The second question that needs to be addressed concerns the quality of care provided to female leprosy patients once the diagnosis has been established. Treatment completion rates can be used as an indirect indicator for the quality of care provided.

Regular monthly visits to the health centre over a longer period are much more likely if a good relationship has been established with the patient and if the need for regular long term treatment has been clearly understood. Treatment completion rates in our program lie between 70 and $80 \%$, a rate that we consider acceptable under the prevailing conditions. Because many of the patients live far away from the treatment centres and access by road is difficult, defaulters cannot always be traced. The fact that women have slightly higher treatment completion rates is reassuring. Health education was given both to men and women, and seemingly there was no difference in comprehension. The fact that less than a quarter of the patients could repeat all four health education messages after a month indicates that the quality of health education needs to be improved. Because of the wide variety of languages spoken, the education can often only be done in Arabic. The fact that hardly any of our patients have had any schooling also plays an important role, the concept of 'the right answer' is often not understood. On this background, it is surprising that there are no larger differences between man and women, as men usually have a much better command of Arabic and are more likely to have had schooling.

The fact that there is no sex difference in the provision of protective footwear is interesting, particularly considering that patients are asked to pay a small fee in order to receive shoes. In a survey conducted among 246 healthy villagers in the area, only $24 \%$ of the women wore shoes compared to $60 \%$ among the men. The explanation given was that women often do not have shoes because they are considered too expensive. This does not seem to apply for protective footwear; it seems to be considered useful enough to warrant the expenditure.

The question of how effective footwear is in preventing episodes of ulceration has been addressed in a separate study (own published data), preliminary analysis of data shows no significant difference between the sexes regarding the occurrence of ulceration and bone loss.

\section{Conclusion}

The data available does not provide any indication that there is discrimination of women within the Guéra Leprosy and Disability Control Project. Women have access to diagnosis 
and treatment and health education. They do not present for treatment later than men, disability rates are lower and they have slightly higher treatment completion rates. Both women and men benefit from footwear. However, a study of the social consequences of leprosy may lead to different conclusions. ${ }^{4}$ Among our patients, we have observed that divorce rates among female leprosy patients are much higher than among men, this has also been documented from other parts of the world. ${ }^{7,34}$ Therefore, it is very likely that women suffer considerably more from the social consequences of the stigma attached to leprosy than men. As this study was not designed to address this issue, this information has not been included. Considering the overall context of this project, the findings with regard to the availability and quality of services are both surprising and reassuring; in this part of central Chad, there is no evidence of disadvantage for women with leprosy in either diagnosis, treatment or follow-up, but more qualitative data are needed to confirm these findings.

\section{Acknowledgements}

The Guéra Leprosy and Disability Control Project is funded by The Leprosy Mission International (TLMI). The author would particularly like to thank Dr Fatchou Gakaitangou and Dr Bambé Lamtoin for their continuous support, advice and encouragement. Marjan de Koning, Yacoub Adoum and Geeske Zijp have made outstanding contributions to the field work. Dr A. C. McDougall's advice in preparing the manuscript has been most valuable.

\section{References}

${ }^{1}$ Ojanuga DN, Gilbert C. Women's access to health care in developing countries. Soc Sci Med, 1992; 35: 613-617.

2 Manderson L, Jenkins J, Tanner M. Women and tropical disease: introduction. Soc Sci Med, 1993; 37: 441-443.

3 Vélez ID, Hendrickx E, Roman R, Agudelo S. Gender and leishmaniasis in Colombia: a redefinition of existing concepts. Gender and Tropical Disease, 1997; 3 (WHO Geneva).

4 Vlassof C, Khot S, Rao S. Double jeopardy: women and leprosy in India. World Health Stat Q, 1996; 49: 120126.

5 Kaur H, Ramesh V. Social Problems of women leprosy patients, Delhi. Lepr Rev, 1994; 65: 361-375.

6 Rao S, et al. Gender issues in the elimination. Quoted in TDR News, 1997, 52.

7 Awofeso N. Effect of socio-cultural beliefs on patients perception of leprosy. The gender factor. Trop Geogr Med, 1995; 47: 175-178.

8 A policy statement on gender. The Leprosy Mission International, Brentford, 1996.

9 Annuaire de Statistiques Sanitaires du Tchad, Année 1995, Tome A, p. 36.

10 Beauvilain A. Tableau de la Population di Tchad des Années Vingt à 1993. Centre National d'Appui à la Recherche, Ndjamena, 1993.

11 Plan National d'Elimination de la Lèpre 1997-2000. Programme National de Lutte Contre la Lèpre, Ndjamena, 1996.

12 Gakaitangou F, Schäfer J. Guide Technique pour la prise en Charge des Cas de Lèpre du Programme National de Lutte Contre la Lèpre, Version 1, 1995.

${ }^{13}$ Gakaitangou F, Schäfer J. Implementing multi drug therapy in areas not covered by the health services-some experiences from Chad (letter). Lepr Rev, 1997; 68: 90-92.

14 WHO: a guide to leprosy control. 2nd edition. World Health Organization, Geneva, 1988.

15 Schäfer J, Currie H, de Koning M, Zijp G. Guéra leprosy and disability control program POD manual, Version 1, 1995.

16 Dean AG. Epi Info Version 6. Centres for Disease Control and Prevention, Atlanta, 1994.

17 Noordeen SK. The epidemiology of leprosy. In: Hastings RC, ed. Leprosy. Churchill Livingstone, Edinburgh, 1994; pp. 29-45.

18 De Rijk AJ, Gabre S, Byass P, Berhanu T. Field evaluation of WHO-MDT of fixed duration at ALERT, Ethiopia: the AMFES project-I. Lepr Rev, 1994; 65: 305-319.

19 Berhe D, Haimanot RT, Tedla T, Taddesse T. Epidemiological pattern of leprosy in Ethiopia: a review of the control programmes. Lepr Rev, 1990; 61: 258-266. 
${ }^{20}$ Ahmed KM, El Tahir MS. The role of village leaders in the implementation of multidrug therapy for leprosy, Sudan-a pilot study in the Angasana Hills. Lepr Rev, 1996; 67: 39-46.

21 Lienhardt C, Kamate B, Jamet P, Tounkara A, Faye OC, Sow SO, Bobin P. Effect of HIV infection on leprosy: a three-year survey in Bamako, Mali. Int J Lepr, 1996; 64: 383-391.

22 Pönnighaus JM, Fine PEM, Sterne JAC, Bliss L, Wilson RJ, Malema SS, Kileta S. Incidence rates of leprosy in Karonga District, Northern Malawi: patterns by age, sex, BCG status and classification. Int J Lepr, 1994; 62: 1023.

${ }^{23}$ Smith WCS, Antin US, Patole AR. Disability in leprosy: a relevant measurement of progress in leprosy control. Lepr Rev, 1980; 51: 155-166.

${ }^{24}$ Rao PSS, Karat S, Karat ABA, Furness MA. Prevalence of deformities and disabilities among leprosy patients in an endemic area. Int J Lepr, 1970; 38: 1-10.

25 Goucheng Z, Wenzhong L, Liangbin Y, Zhongmin Y, Xiangsheng C, Tisheng Z, Ganyun Y. An epidemiological survey of deformities and disabilities among 14,257 cases of leprosy in 11 countries. Lepr Rev, 1993; 64: 143149.

${ }^{26}$ Ponninghaus IM, Boerrigter G, Fine PEM, Ponnighaus JM, Russell J. Disabilities in leprosy patients ascertained in a total population survey in Karonga District, Northern Malawi. Lepr Rev, 1990; 61: 366-374.

27 Tiendrebeogo A, Toure I, Zerbo P. A survey of leprosy impairments and disabilities among patients treated by MDT in Burkina Faso. Int J Lepr, 1996; 64: 15-25.

28 al-Kandari S, al-Anezi A, Pugh RN, al-Qasaf, al-Abyad S. Leprosy in Kuwait: an epidemiological study of new cases. Ann Trop Med Parasitol, 1990; 84: 513-522.

29 Smith WCS, Antin US, Patole AR. Disability in leprosy: a relevant measurement of progress in leprosy control. Lepr Rev, 1980; 51: 155-166.

${ }^{30}$ Rao PSS, Karat S, Karat ABA, Furness MA. Prevalence of deformities and disabilities among leprosy patients in an endemic area. Int J Lepr, 1970; 38: 1-10.

31 Goucheng Z, Wenzhong L, Liangbin Y, Zhongmin Y, Xiangsheng C, Tisheng Z, Ganyun Y. An epidemiological survey of deformities and disabilities among 14,257 cases of leprosy in 11 countries. Lepr Rev, 1993; 64: 143149.

32 Ponninghaus IM, Boerrigter G, Fine PEM, Ponnighaus JM, Russel J. Disabilities in leprosy patients ascertained in a total population survey in Karonga District, Northern Malawi. Lepr Rev, 1990; 61: 366-374.

33 Tiendrebeogo A, Toure I, Zerbo P. A survey of leprosy impairments and disabilities among patients treated by MDT in Burkina Faso. Int J Lepr, 1996; 64: 15-25.

34 Eidarous AH, Kamel Z, Ahmad F. Divorce among Saudi female leprotic patients: an experience at Ibn Sina Hospital. Lepr Rev, 1993; 64: 166-169. 